\title{
Co-treatment of waste printed circuit boards and polyvinyl chloride by subcritical water oxidation: Removal of brominated flame retardants and recovery of $\mathrm{Cu}$ and $\mathrm{Pb}$
}

\author{
Fu-Rong Xiu ${ }^{\text {a,c,* }}$, Yingying Qi ${ }^{a}$, Fu-Shen Zhang ${ }^{b}$ \\ ${ }^{a}$ Department of Environment and Equipment Engineering, Fujian University of Technology, Fuzhou 350108, People's Republic of China \\ ${ }^{\mathrm{b}}$ Research Center for Eco-Environmental Sciences, Chinese Academy of Sciences, Beijing 100085, People's Republic of China \\ ${ }^{\mathrm{c}}$ Key Laboratory of Solid Waste Treatment and Recycle (SWUST), Ministry of Education, Mianyang 621010, People's Republic of China
}

\section{H I G H L I G H T S}

-We report an effective process for co-treatment of waste PCBs and PVC.

- Brominated flame retardants can be decomposed efficiently in co-treatment.

- Dechlorination of PVC was complete and safe.

- $\mathrm{Cu}$ and $\mathrm{Pb}$ in waste printed circuit boards can be recovered efficiently.

- Sn and $\mathrm{Cr}$ can be immobilized efficiently in the residue after co-treatment.

\section{A R T I C L E I N F O}

\section{Article history:}

Received 27 May 2013

Received in revised form 6 October 2013

Accepted 10 October 2013

Available online 19 October 2013

\section{Keywords:}

WEEE

Waste PCBs

PVC

Subcritical water oxidation

\begin{abstract}
A B S T R A C T
In this work, an effective process for removal of brominated flame retardants (BFRs) and recovery of Cu and $\mathrm{Pb}$ from waste printed circuit boards (PCBs) was developed. In the process, waste PCBs and polyvinyl chloride (PVC) were co-treated by subcritical water oxidation (SBWO). PVC was used as a hydrochloric acid source and waste $\mathrm{PCBs}$ was used as a neutralizing reagent for the produced $\mathrm{HCl}$. The dechlorination of PVC, removal of BFRs, and recovery of $\mathrm{Cu}$ and $\mathrm{Pb}$ could be achieved simultaneously by the one-step SBWO reaction. Experimental results showed that the dechlorination of PVC was complete when SBWO temperature exceeded $250^{\circ} \mathrm{C}$. SBWO co-treatment was high efficient for the leaching of $\mathrm{Cu}$ and $\mathrm{Pb}$ from waste PCBs, and XRD spectra indicated that $\mathrm{Sn}$ was immobilized as $\mathrm{SnO}_{2}$ in the residue after co-treatment. The optimum SBWO co-treatment conditions were temperature of $350^{\circ} \mathrm{C}$, time of $60 \mathrm{~min}$, solidliquid ratio of $1: 9 \mathrm{~g} / \mathrm{ml}$, and PVC-to-PCBs ratio of $1: 1$, respectively. In the optimized co-treatment, 98.9\% of $\mathrm{Cu}$ and $80 \%$ of $\mathrm{Pb}$ were recovered, while the leaching efficiencies of $\mathrm{Sn}$ and $\mathrm{Cr}$ were $15.3 \%$ and $3.9 \%$, respectively. Meanwhile, approximately $100 \%$ of the bromine was changed into $\mathrm{HBr}$ and enriched in water after co-treatment.
\end{abstract}

(c) 2013 Elsevier B.V. All rights reserved.

\section{Introduction}

Waste electric and electronic equipment (WEEE) has been taken into consideration not only by the government but also by the public due to its content of valuable materials and hazardous matters [1]. As the primary elements in most WEEE, printed circuit boards (PCBs) are widely used as the platform upon which microelectronic components such as semiconductor chips and capacitors are mounted. Waste PCBs contain approximately 70\% nonmetals and

\footnotetext{
* Corresponding author at: Department of Environment and Equipment Engineering, Fujian University of Technology, Fuzhou 350108, People's Republic of China. Tel.: +8659122863268.

E-mail address: xiu_chem@hotmail.com (F.-R. Xiu).
}

$30 \%$ metals [2]. The nonmetal portions of waste PCBs consist of resins and brominated flame retardants (BFRs) [3]. Improper disposition of waste PCBs may cause serious pollution due to the formation of brominated dioxin-like compounds from BFRs [4]. The typical metals in waste PCBs consist of $\mathrm{Cu}, \mathrm{Pb}, \mathrm{Sn}, \mathrm{Cr}, \mathrm{Cd}, \mathrm{Zn}, \mathrm{Ni}$, and $\mathrm{Mn}$ [5]. Previous study [6], using the toxicity characteristic leaching procedure (TCLP) of the US Environmental Protection Agency (USEPA), indicated that Pb (around 2\% in PCBs) concentrations in the extracts of a vast majority of the PCBs were higher than the limit levels. On the other hand, the quantity of valuable metal such as $\mathrm{Cu}$ (around 20\% in PCBs) turns the wastes into an interesting raw material from the economic point of view.

Currently, pyrometallurgical process [7,8] and hydrometallurgical process [9-11] are the two traditional approaches for the 
recovery of metals from waste PCBs. In addition, many researchers have used various mechanical methods as pre-treatment to separate metals from waste PCBs $[2,5]$. Other recycling techniques for metals in waste PCBs such as bioleaching $[12,13]$ and vacuum metallurgy technology [14] also have been developed. However, the foregoing processes not only can not remove efficiently toxic organic matters such as BFRs in waste PCBs, but also have a considerable loss of valuable metal due to the insufficient liberation $[15,16]$. Among various recovery technologies, hydrometallurgical processes with relatively low capital costs and suitability for small scale applications are promising options for the treatment of waste PCBs, and the leaching of metals is the most important procedure in a hydrometallurgical process [11]. However, the metals and polymers in waste PCBs are intermingled very much and also have other materials embedded inside, which is the main obstacle for the leaching of metals from waste PCBs.

In recent years, sub- and supercritical water (sub/SCW) is used as an environment-friendly method to decompose hazardous matters due to its extraordinary properties, such as low viscosities, high mass transport coefficient, high diffusivity and high solubility for organics $[17,18]$. In sub/SCW conditions, water can act not only as a solvent but also as a reactant, catalyst or product due to the different properties in different temperature and pressure [19]. Onwudili and Williams $[20,21]$ found that pure flame-retarded plastics could be degraded effectively in sub/SCW and brominefree oil could be obtained by adding alkaline additives. Yin and Xing [22,23] also reported that toxic organic matters such as BFRs in waste PCBs could be degraded efficiently in sub/SCW under reducing atmosphere, and the formation of toxic brominated organic compounds was eliminated at the same time. However, little is known about the debromination behavior of BFRs during the subcritical water oxidation (SBWO) process in the presence of oxygen.

In our latest study [24], a two-step process for metals recovery from waste PCBs by supercritical water pre-treatment combined with acid leaching was developed. In the proposed process, waste PCBs were pre-treated by supercritical water, then the separated solid phase product with concentrated metals was subjected to an acid leaching process for metals recovery. In this work, we attempted to develop a highly efficient one-step process for the treatment of waste PCBs by SBWO reaction, in which the removal of BFRs and the recovery of $\mathrm{Cu}$ and $\mathrm{Pb}$ from PCBs could be achieved simultaneously. In the process, another waste, polyvinyl chloride (PVC), was introduced into the SBWO reaction system of waste PCBs in consideration of the ubiquity of PVC plastics in WEEE. Currently, PVC wastes are mainly incinerated for thermal recovery. However, the incineration of PVC can lead to the formation of chlorinated toxic organics such as dioxins [25,26]. Hence, it is important for PVC waste to be treated in a safe process. In the co-treatment of waste PCBs and PVC, the lixiviant $(\mathrm{HCl})$ in situ generated by $\mathrm{PVC}$ decomposition is expected to extract $\mathrm{Cu}$ and $\mathrm{Pb}$ from waste PCBs. In other words, by co-treating the two wastes in SBWO, waste PCBs is used as both a secondary source for metals and a neutralizer for $\mathrm{HCl}$ from waste PVC, and PVC waste is used as an acid source for the leaching of metals in PCBs. Meanwhile, the BFRs contained in waste PCBs can be removed safely during the co-treatment. Hence, the dechlorination of PVC, the debromination of BFRs, and the leaching of metals would occur in the same reaction system, which is quite different from the process in our previous report [24]. During the co-treatment system, the characteristics and influence factors of dechlorination, debromination, and metals leaching are needed to be clarified. The objectives of the present work are (1) to evaluate the dechlorination behavior of PVC in the SBWO process, (2) to examine the removal efficiency of BFRs from waste PCBs in the co-treatment process, and (3) to investigate the effects of mixing ratio of waste PVC to PCBs, co-treatment temperature, time, and solid-liquid ratio on the leaching activity of different metals contained in waste PCBs. $\mathrm{Cu}$, $\mathrm{Pb}, \mathrm{Sn}$, and $\mathrm{Cr}$ were selected as target elements, among which $\mathrm{Cu}$ is the richest metallic element in waste PCBs, while $\mathrm{Pb}, \mathrm{Sn}$, and $\mathrm{Cr}$ are of environmental and public health concern.

\section{Materials and methods}

\subsection{Materials}

Waste PCBs used in this work were mainly collected and disassembled from discarded telephones, PCs, and other electrical equipments. After the components (relays, capacitors, etc.) were disassembled, the PCBs were sent to be comminuted in a cutting mill until the particle size $<1 \mathrm{~mm}$. The composition of the waste PCBs sample is given in Table 1. The CHNSO content of the PCBs samples was measured by an Elemental Analyzer (vario EL, Elementar Analysensysteme $\mathrm{GmbH}$ ). A commercially available poly(vinyl chloride) (PVC) (DAXIANG Chemical Company of Beijing, degree of polymerization $\approx 1100$ ) was used in this study. The diameter of the PVC powder was around $500 \mu \mathrm{m}$. Other chemicals used in this study were purchased from Chemical Reagent Company of Beijing in analytical grade and all of them were used as received.

\subsection{SBWO co-treatment of waste PCBs and PVC}

The SBWO co-treatment experiments were carried out in a 200$\mathrm{ml}$ high-pressure reactor made of 316 alloy (WYF-2 from HUAAN, China). The mixture of waste PCBs, PVC and different amounts of distilled water were introduced into the reactor, while $40 \mathrm{ml}$ of hydrogen peroxide $\left(\mathrm{H}_{2} \mathrm{O}_{2}, 30 \mathrm{wt} . \%\right)$ was used as oxygen source [19]. $\mathrm{H}_{2} \mathrm{O}_{2}$ was decomposed and the released $\mathrm{O}_{2}$ was dissolved in subcritical water $\left(\mathrm{H}_{2} \mathrm{O}_{2}=\mathrm{H}_{2} \mathrm{O}+1 / 2 \mathrm{O}_{2}\right)$. The amount of waste PCBs used in every experiment was $5 \mathrm{~g}$. The adding volume of water was controlled at $10,20,30,40,50$, and $60 \mathrm{ml}$, respectively. The reaction temperature was varied from 150 to $400{ }^{\circ} \mathrm{C}$, and the residence time was controlled at $30,60,90,120,150$, and $180 \mathrm{~min}$, respectively. The reactor was heated to selected temperatures, and kept at these temperatures for selected residence time. The increase of temperature was at the rate of $10{ }^{\circ} \mathrm{C}$ per minute. The mixing ratios of PVC to PCBs were controlled at $0: 1,0.25: 1,0.5: 1,1: 1$ and 1.5:1 $(w / w)$, respectively. The pressure inside was monitored by a pressure gauge attached to the reactor. The pressure in the reactor was changed during the reaction process and whose value depended upon the reaction conditions and the filling rate of the reactor. When the reactor was heated to selected temperature, the pressure at this point was defined as the initial pressure. After that, the reaction was held at this temperature for selected residence time. The pressure inside was defined as the final pressure when the residence time reached the selected value. The reaction conditions of each experiment were described in Table 2.

Table 1

Composition of the waste PCBs sample.

\begin{tabular}{lc}
\hline Element & Content $(\% \mathrm{w} / \mathrm{w})$ \\
\hline $\mathrm{Cu}$ & $25.00 \pm 0.05$ \\
$\mathrm{~Pb}$ & $1.90 \pm 0.03$ \\
$\mathrm{Sn}$ & $5.90 \pm 0.06$ \\
$\mathrm{Cr}$ & $0.04 \pm 0.02$ \\
$\mathrm{C}$ & $23.62 \pm 0.07$ \\
$\mathrm{H}$ & $2.73 \pm 0.03$ \\
$\mathrm{~N}$ & $1.21 \pm 0.04$ \\
$\mathrm{~S}$ & $0.02 \pm 0.01$ \\
$\mathrm{O}$ & $16.84 \pm 0.06$ \\
\hline
\end{tabular}


Table 2

Conditions of co-treatment experiments ( $P_{i}$ : initial pressure; $P_{f}$ : final pressure).

\begin{tabular}{rlclcc}
\hline Experiment & $\begin{array}{l}\text { Temperature } \\
\left({ }^{\circ} \mathrm{C}\right)\end{array}$ & $\begin{array}{l}\text { Time } \\
(\mathrm{min})\end{array}$ & $\begin{array}{l}\text { PVC-to-PCBs } \\
\text { ratio }\end{array}$ & $\begin{array}{l}P_{i} \\
(\mathrm{MPa})\end{array}$ & $\begin{array}{l}P_{f} \\
(\mathrm{MPa})\end{array}$ \\
\hline 1 & 150 & 60 & $1: 1$ & 1 & 2 \\
2 & 200 & 60 & $1: 1$ & 4 & 5 \\
3 & 250 & 60 & $1: 1$ & 10 & 12 \\
4 & 300 & 60 & $1: 1$ & 15 & 17 \\
5 & 350 & 60 & $1: 1$ & 18 & 20 \\
6 & 400 & 60 & $1: 1$ & 23 & 25 \\
7 & 350 & 30 & $1: 1$ & 18 & 19 \\
8 & 350 & 90 & $1: 1$ & 18 & 21 \\
9 & 350 & 120 & $1: 1$ & 18 & 22 \\
10 & 350 & 150 & $1: 1$ & 18 & 22 \\
11 & 350 & 180 & $1: 1$ & 18 & 22 \\
12 & 350 & 60 & $0: 1$ & 12 & 14 \\
13 & 350 & 60 & $0.25: 1$ & 13 & 15 \\
14 & 350 & 60 & $0.5: 1$ & 16 & 17 \\
16 & 350 & 60 & $1.5: 1$ & 19 & 21 \\
\hline
\end{tabular}

Three phases (solid, aqueous, and gaseous) were produced after reaction. After each SBWO co-treatment, the gaseous phase was passed through a $\mathrm{NaHCO}_{3}$ solution to capture inorganic bromine. Solid phase and aqueous phase were separated using a vacuum filter (VF204A from LEADER, China). The obtained solid residue was dried in an oven (DHG-9055A from HASCU, China) at $105^{\circ} \mathrm{C}$ overnight for subsequent characterization. The bromine content in the solid sample was measured by an oxygen combustion bomb-ion chromatography (IC, DionexICS2000, USA). Because the high content of metals contained in PCBs and the reactions between metals and $\mathrm{Br}$ during the oxygen combustion process may result in the formation of insoluble $\mathrm{Br}$-contained products and influence the determination of $\mathrm{Br}$, the sulfuric acid $-\mathrm{H}_{2} \mathrm{O}_{2}$ leaching system was used to remove the metals prior to the analysis of $\mathrm{Br}$. The digestion-measurement process is as follows: $50 \mathrm{ml} \mathrm{H}_{2} \mathrm{O}_{2}$ solution (30 wt.\%) was added in $50 \mathrm{ml}$ sulfuric acid solution $\left(\mathrm{H}_{2} \mathrm{SO}_{4}: \mathrm{H}_{2}\right.$ $\mathrm{O}=1: 3$ ), and then $5 \mathrm{~g}$ PCBs sample was introduced into the $\mathrm{H}_{2} \mathrm{SO}_{4}-\mathrm{H}_{2} \mathrm{O}_{2}$ leaching solution. After the reaction of $24 \mathrm{~h}$, the solution was filtrated and the filtrate was diluted to $250 \mathrm{ml}$. The $\mathrm{Br}$ may exist in filtrate (mainly inorganic bromine) and solid residue (mainly organic bromine). Then $0.2 \mathrm{ml}$ of $0.2 \mathrm{~mol} / \mathrm{l} \mathrm{KI}$ solution was added into $0.5 \mathrm{ml}$ of the diluted filtrate. After that, the obtained solution was diluted to $100 \mathrm{ml}$ and bromine content (C1) was measured by ion chromatography. The obtained solid residue was dried at $105^{\circ} \mathrm{C}$ for $3 \mathrm{~h}$ in an oven, then $0.5 \mathrm{~g}$ of the dried residue was introduced into the oxygen combustion bomb and $1 \mathrm{ml}$ ethanol was added as combustion improver at the same time. Before combustion reaction, $40 \mathrm{ml}$ of $0.5 \mathrm{~mol} / 1 \mathrm{NaOH}$ solution was added to absorb the produced bromine. Then $0.2 \mathrm{~mol} / \mathrm{l} \mathrm{KI}$ was added into the combusted solution and the bromine content (C2) was determined by ion chromatography after dilution. The bromine content in the solid sample was the summation of $\mathrm{C} 1$ and $\mathrm{C} 2$. The standard deviations on these values of bromine contents are $\leqslant \pm 0.08$. Debromination ratio was calculated according to the content of bromine before and after the co-treatment.

Metals contents in raw PCBs sample were measured by ICP-OES (OPTIMA 2000, PerkinElmer) after digestion [9]. Metals concentrations in the solutions after SBWO co-treatments were also measured by ICP-OES and the pHs of the solutions were measured by a Radiometer Analytical pH electrode (PHS-3D, LEICI). The metal leaching efficiency is defined as follows:

Metal leaching efficiency $(\%)=W_{1} \times 100 / W_{2}$

where $W_{1}$ is the metal mass leached and $W_{2}$ the initial metal mass in waste PCBs sample.

The structure of the solid residue obtained after SBWO co-treatment was characterized by X-ray diffraction spectroscopy (XRD,
Bruker D8 X-ray powder diffractometer) at $50 \mathrm{kV}$ and $100 \mathrm{~mA}$ using $\mathrm{Cu} \mathrm{K} \alpha$ radiation $(\lambda=1.5418 \AA$ ).

\subsection{PVC dechlorination in SBWO process}

The PVC dechlorination experiments also were carried out in the 200-ml high-pressure reactor which was the same as the one used in SBWO co-treatment. $5 \mathrm{~g}$ PVC and $50 \mathrm{ml}$ distilled water were introduced into the reactor, and then $40 \mathrm{ml} \mathrm{H}_{2} \mathrm{O}_{2}$ was added. The operation details are the same as the SBWO co-treatment experiments. After each reaction, the gaseous phase was passed through a $\mathrm{NaHCO}_{3}$ solution with the purpose of capturing inorganic chlorine, and the liquid-solid mixture was filtered by a vacuum filter. Ion chromatography was applied for the analysis of the chlorine content in the solution.

The content of chlorine in raw PVC and in SBWO-treated PVC residue was also analyzed by the oxygen combustion bomb-ion chromatography. The detail of the determination of $\mathrm{Cl}$ in the samples is the same as the $\mathrm{Br}$. The standard deviations on the values of $\mathrm{Cl}$ contents are $\leqslant \pm 0.06$. The content of chlorine in raw PVC is $56.2 \pm 0.06$ wt.\%. Dechlorination ratio was calculated according to the $\mathrm{Cl}$ content before and after the SBWO treatment.

\section{Results and discussion}

\subsection{Dechlorination behavior of PVC in SBWO process}

To investigate the dechlorination behavior of PVC in SBWO process, the percentages of the PVC dechlorination were examined under different conditions, including reaction temperature and residence time. The effect of reaction temperature on the PVC dechlorination is shown in Fig. 1a. The reaction temperature was varied from 150 to $400{ }^{\circ} \mathrm{C}$. No noticeable dechlorination of PVC was observed below $200^{\circ} \mathrm{C}$. The dechlorination increased significantly above $200{ }^{\circ} \mathrm{C}$, and reached $93 \%$ at $250^{\circ} \mathrm{C}$. It was reported that in this temperature region the dechlorination of PVC occurred by thermal degradation [26]. Takeshita et al. [25] also reported that the PVC dechlorination was controlled by thermal degradation in water with saturated pressure. Similar behavior of PVC was observed in the presence of oxygen in our SBWO process. The dechlorination reached approximately $100 \%$ after treatment for the temperature $\geqslant 300^{\circ} \mathrm{C}$. To investigate the distribution of $\mathrm{Cl}$ decomposed from PVC in products after SBWO process, the $\mathrm{Cl}$ contents in gaseous product and aqueous phase product were analyzed. It was found that the $\mathrm{Cl}$ decomposed from PVC during SBWO process was completely transferred to aqueous phase, indicating that nearly all of the $\mathrm{Cl}$ in PVC could be dissolved as $\mathrm{HCl}$ in water in the temperatures varied from 300 to $400^{\circ} \mathrm{C}$.

Fig. 1b shows the effect of residence time on the dechlorination of PVC at $350{ }^{\circ} \mathrm{C}$. The PVC dechlorination at $30 \mathrm{~min}$ was $96 \%$, and then reached a stable level at around $100 \%$ for all residence time studied. The results indicated that the dechlorination did not depend upon the residence time after $30 \mathrm{~min}$. Therefore, we infer that 30 min is sufficient for all of the $\mathrm{Cl}$ in PVC to be dissolved as $\mathrm{HCl}$ in water in SBWO process at $350^{\circ} \mathrm{C}$.

\subsection{Debromination behavior of waste PCBs in SBWO co-treatment}

The effect of temperature on the debromination of waste PCBs in SBWO co-treatment is shown in Fig. 2a. No debromination could be found when the temperature was $<200^{\circ} \mathrm{C}$, which could be attributed to that the energy provided by the system was not enough to break chemical bond of BFRs. The debromination efficiency increased quickly with the increase of temperature. The debromination efficiency reached approximately $100 \%$ at $350{ }^{\circ} \mathrm{C}$. The results 

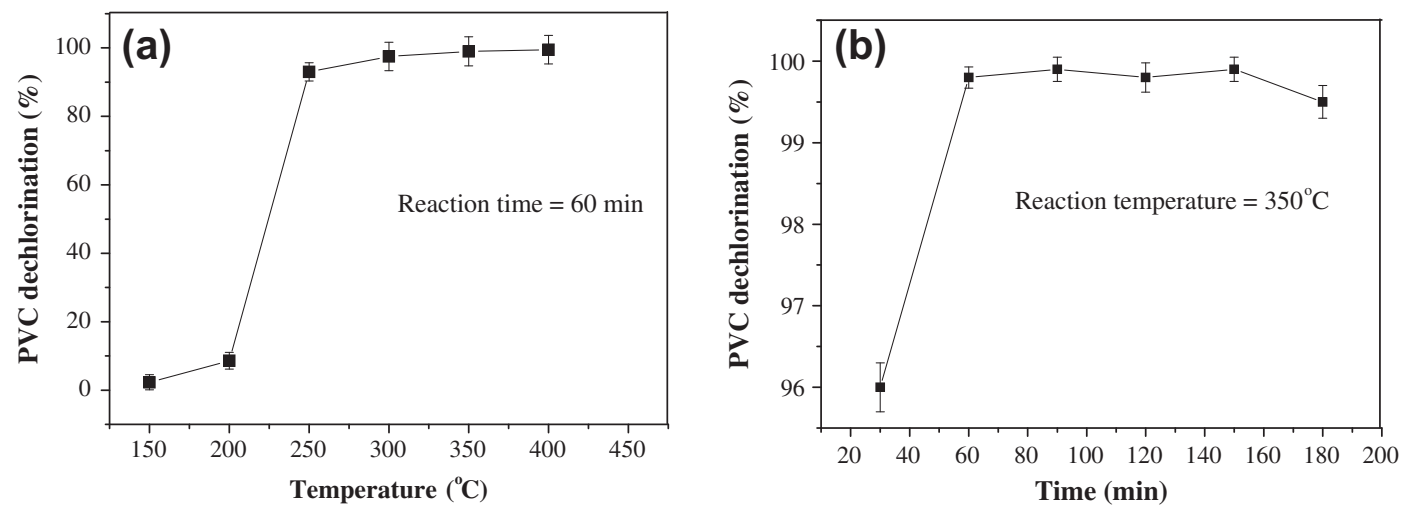

Fig. 1. Effects of (a) temperature and (b) time on PVC dechlorination.

showed that temperature was an important influence factor on debromination efficiency. The temperature region in which the $\mathrm{HBr}$ was released from BFRs was between 200 and $300^{\circ} \mathrm{C}$. It has been reported that in traditional thermal degradation process, BFRs was decomposed from $297{ }^{\circ} \mathrm{C}$ to $400{ }^{\circ} \mathrm{C}$ [27]. Hence, compared with the traditional thermal degradation process, the degradation temperature region of BFRs can be obviously reduced under the SBWO reaction conditions.

Fig. 2b shows the effect of residence time on the debromination of waste PCBs in SBWO co-treatment. BFRs in waste PCBs could be decomposed rapidly in the first $30 \mathrm{~min}$ (98.5\%). $\mathrm{HBr}$ and aromatics were released with the decomposition of BFRs. In subcritical region, dissolving capacity of organic molecules and oxygen in water is enhanced significantly due to the low dielectric constant of water, which causes water to behave more like an organic solvent and allows reaction to proceed rapidly by an elimination of the potential interface mass transport limitations [28]. Therefore, the aromatics produced from BFRs could be oxidized to $\mathrm{CO}_{2}$ and $\mathrm{H}_{2} \mathrm{O}$ quickly in the SBWO co-treatment. When the residence time was $>30 \mathrm{~min}$, the debromination increased slightly with the increase of time. Considering the debromination efficiency and energy consume, it is recommended that $\mathbf{3 0 - 9 0 ~} \mathrm{min}$ is the optimum residence time range.

After each experiment, gas phase product was introduced into $\mathrm{NaHCO}_{3}$ solution to capturing $\mathrm{HBr}$. However, the results indicated that no inorganic bromine was detected in the gas phase product in all experiments. Because $\mathrm{HBr}$ has a high solubility in water, it could be completely transferred into water during the cooling process after reaction.
3.3. Effect of the mixing ratio of PVC to PCBs on the leaching of different metals in SBWO co-treatment

To investigate the effect of the mixing ratio of PVC to PCBs on the leaching of metals in co-treatment, different PVC-to-PCBs ratios $(0: 1,0.25: 1,0.5: 1,1: 1$, and $1.5: 1)$ were used in experiments at $350{ }^{\circ} \mathrm{C}$ and $60 \mathrm{~min}$. The results are shown in Fig. 3. The leaching of all metals studied was negligible when no PVC was introduced into the reaction system. In the experiment with the PVC-to-PCBs ratio of $0.25: 1,14.9 \%$ of the $\mathrm{Cu}, 5.7 \%$ of the $\mathrm{Pb}, 3.6 \%$ of the $\mathrm{Sn}$, and $0.2 \%$ of the $\mathrm{Cr}$ were converted from insoluble species to soluble species. With further increasing the PVC-to-PCBs ratio, there was little change in the concentration of $\mathrm{Sn}$ and $\mathrm{Cr}$ in the aqueous phase, while the leachability of $\mathrm{Cu}$ and $\mathrm{Pb}$ tended to increase remarkably. The leaching of $\mathrm{Cu}$ and $\mathrm{Pb}$ in aqueous phase rose from $14.9 \%$ and $5.7 \%(\mathrm{PVC} / \mathrm{PCBs}=0.25)$ to $98.9 \%$ and $80 \%(\mathrm{PVC} / \mathrm{PCBs}=1)$, respectively. Afterwards, the leaching of $\mathrm{Cu}$ and $\mathrm{Pb}$ changed slightly with further increasing the PVC-to-PCBs ratio. Also, it can be found in Fig. 3 that the leaching of $\mathrm{Sn}$ and $\mathrm{Cr}$ began to increase slowly when the PVC-to-PCBs ratio was $>0.5$. The experiment results indicated that during the co-treatment process, the leaching of $\mathrm{Cu}$ and $\mathrm{Pb}$ was prior to $\mathrm{Sn}$ and $\mathrm{Cr}$ in the presence of $\mathrm{HCl}$, which was derived from the decomposition of PVC, when the PVC-toPCBs ratio was controlled at 1:1 (Fig. 3).

The leaching efficiency of $\mathrm{Cr}$ was very low (approximately $0 \%$ ) at low mixing ratios of PVC to PCBs (PVC:PCBs $<1: 1$ ). In the co-treatment process, PVC was decomposed to produce $\mathrm{HCl}$ at a shorter time according to the dechlorination experiment. $\mathrm{Cr}^{3+}$ could be formed by the reactions between $\mathrm{Cr}^{0}$ and $\mathrm{HCl}$.
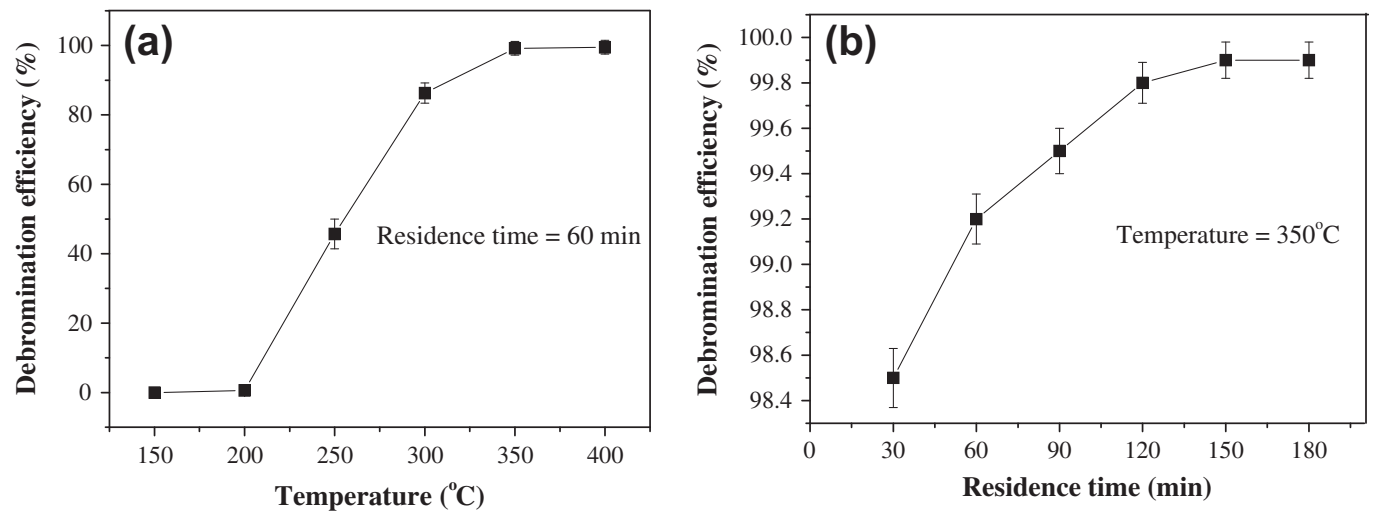

Fig. 2. Effects of (a) temperature and (b) time on debromination efficiency of waste PCBs. 


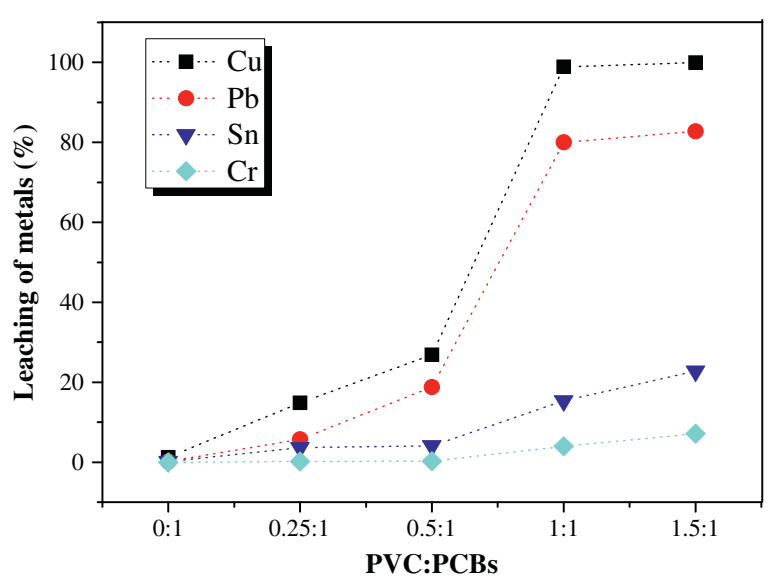

Fig. 3. Effect of the mixing ratio of $P V C$ to $P C B s$ on the leaching of different metals in co-treatment (reaction temperature $=350{ }^{\circ} \mathrm{C}$, reaction time $=60 \mathrm{~min}$, solidliquid ratio $=1: 9$ )

$\mathrm{Cr}+2 \mathrm{HCl}=\mathrm{CrCl}_{2}+\mathrm{H}_{2}$

$4 \mathrm{CrCl}_{2}+4 \mathrm{HCl}+\mathrm{O}_{2}=4 \mathrm{CrCl}_{3}+2 \mathrm{H}_{2} \mathrm{O}$

In the SBWO co-treatment process, soluble chromate could be formed by the oxidation of $\mathrm{Cr}^{3+}$ due to the high temperature, high pressure and oxidizing atmosphere [29]. The interaction between chromate and $\mathrm{Pb}$ species could result in the formation of insoluble $\mathrm{PbCrO}_{4}$ [29]. Because of the higher mole ratio of $\mathrm{Pb} / \mathrm{Cr}(12 / 1)$ in our study, we infer that the $\mathrm{Cr}$ can be thoroughly converted from soluble chromate to insoluble $\mathrm{PbCrO}_{4}$ at $350{ }^{\circ} \mathrm{C}$ and $60 \mathrm{~min}$. With increasing the mixing ratio of PVC to PCBs (PVC:PCBs $\geqslant 1: 1$ ), the leaching of $\mathrm{Cr}$ tended to increase slightly. The variation tendency of $\mathrm{Sn}$ leaching was very similar with that of $\mathrm{Cr}$. Fig. $4 \mathrm{a}$ and $\mathrm{b}$ shows $\mathrm{X}$-ray diffraction spectra measured for the residues of waste PCBs and PVC co-treated at $200{ }^{\circ} \mathrm{C}$ and $400{ }^{\circ} \mathrm{C}$, respectively. A considerable part of $\mathrm{Sn}$ was oxidized to $\mathrm{SnO}_{2}$ quickly even at $200{ }^{\circ} \mathrm{C}$ in the SBWO co-treatment according to XRD analysis. There are no significant reactions between $\mathrm{SnO}_{2}$ and $\mathrm{HCl}$, resulting in a low leaching efficiency of $\mathrm{Sn}$ at low mixing ratios of PVC to PCBs (PVC:PCBs $\leqslant 0.5: 1$ ). The leaching of $\mathrm{Sn}$ and $\mathrm{Cr}$ increased slightly when the mixing ratio of PVC to PCBs was $\geqslant 1: 1$, which could be attributed to the excess $\mathrm{HCl}$ and the noticeable decline of $\mathrm{pH}$ in the co-treatment system. To study the effect of the mixing ratio of PVC to PCBs on $\mathrm{pH}$, the system $\mathrm{pH}$ after co-treatment at different mixing ratios was measured. The results are given in Fig. 5. The system $\mathrm{pH}$ decreased from 6.5 to 1.0 with the increase of the mixing ratio of PVC to PCBs from 0:1 to 1.5:1.

In the co-treatment process, $\mathrm{H}_{2} \mathrm{O}_{2}$ was decomposed and the released $\mathrm{O}_{2}$ was dissolved in subcritical water. Oxygen can react with metal copper to form cupric oxide, which can further react with hydrochloric acid to form copper chloride. It can be found in Fig. 5 that the system pH was higher than 4.3 when the PVC-toPCBs ratio $\leqslant 0.5: 1$. Because copper (II) may precipitate as hydroxy chloride even at pHs as low as 2-3, a notable proportion of the $\mathrm{Cu}$ cannot be leached in the co-treatment system (Fig. 3). However, with further increasing the PVC-to-PCBs ratio, the leaching of $\mathrm{Cu}$ was enhanced remarkably. The leaching of $\mathrm{Cu}$ reached $98.9 \%$ when the PVC-to-PCBs ratio was increased to $1: 1$ (Fig. 3). This could be attributed to the rapid falling of the system pH (Fig. 5). The pH declined to 1.8 at the PVC-to-PCBs ratio of $1: 1$. An evaporation-concentration-cooling-crystallization process was conducted for the metals recovery from the leaching solution. The product from crystallization of leaching solution was examined by XRD technique. The XRD pattern of the product is showed in Fig. 6, which is a pure $\mathrm{CuCl}_{2} \cdot 2 \mathrm{H}_{2} \mathrm{O}$ pattern according to the analysis result. (b)

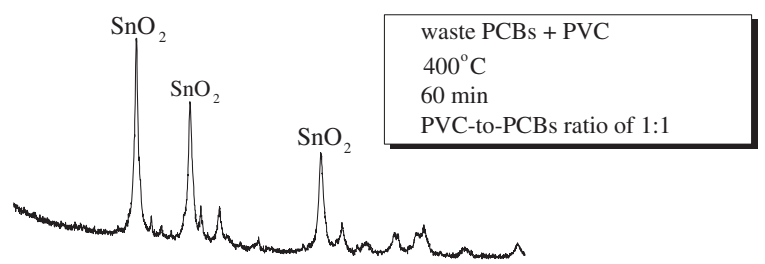

(a)
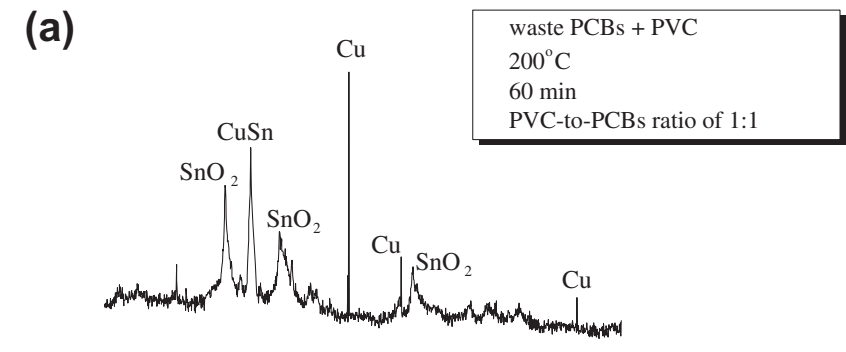

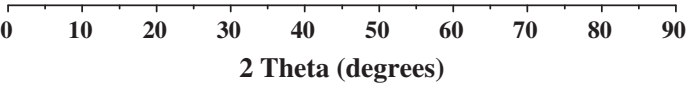

Fig. 4. X-ray diffraction patterns of the solid residue from SBWO co-treated (PCBs + PVC) at PVC-to-PCBs ratio of 1:1.

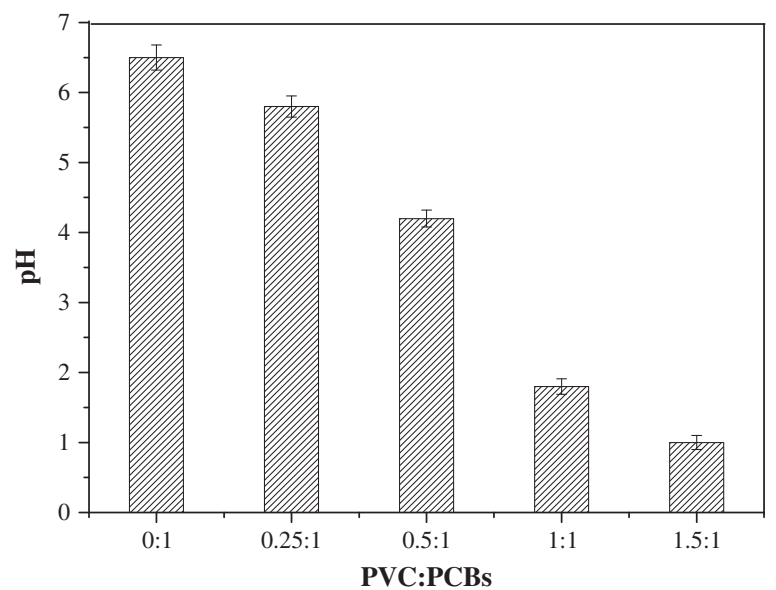

Fig. 5. Effect of the mixing ratio of PVC to PCBs on the system pH (reaction temperature $=350^{\circ} \mathrm{C}$, reaction time $=60 \mathrm{~min}$, solid-liquid ratio $=1: 9$ ).

In the co-treatment process with the mixing ratio of $0.25: 1, \mathrm{~Pb}$ could not only be converted to insoluble $\mathrm{PbCl}_{2}$ by the reaction with $\mathrm{HCl}$ decomposed from PVC, but also be oxidized and further react with $\mathrm{CrO}_{4}^{2-}$ to form insoluble $\mathrm{PbCrO}_{4}$. The $\mathrm{CrO}_{4}^{2-}$ was derived from the oxidation of $\mathrm{Cr}$ in the SBWO process [29]. With further increasing the mixing ratio of PVC to PCBs, the influence of mixing ratio on the leaching of $\mathrm{Pb}$ was similar to that of $\mathrm{Cu}$. When the mixing ratio of PVC to PCBs was increased to $1: 1$, approximately $80 \%$ of the $\mathrm{Pb}$ was leached due to the excess $\mathrm{HCl}$, which could form stable complexes with $\mathrm{Pb}[30]$.

\subsection{Effect of temperature on the leaching of different metals in SBWO co-treatment}

Fig. 7 shows the effect of co-treatment temperature on the leaching of different metals at temperatures ranging from $150{ }^{\circ} \mathrm{C}$ to $400{ }^{\circ} \mathrm{C}$ for $60 \mathrm{~min}$. The leaching of all metals studied was negligible when co-treatment temperature was below $200{ }^{\circ} \mathrm{C}$. This could be attributed to the inefficient dechlorination of PVC below $200{ }^{\circ} \mathrm{C}$ according to the dechlorination experiments. With 


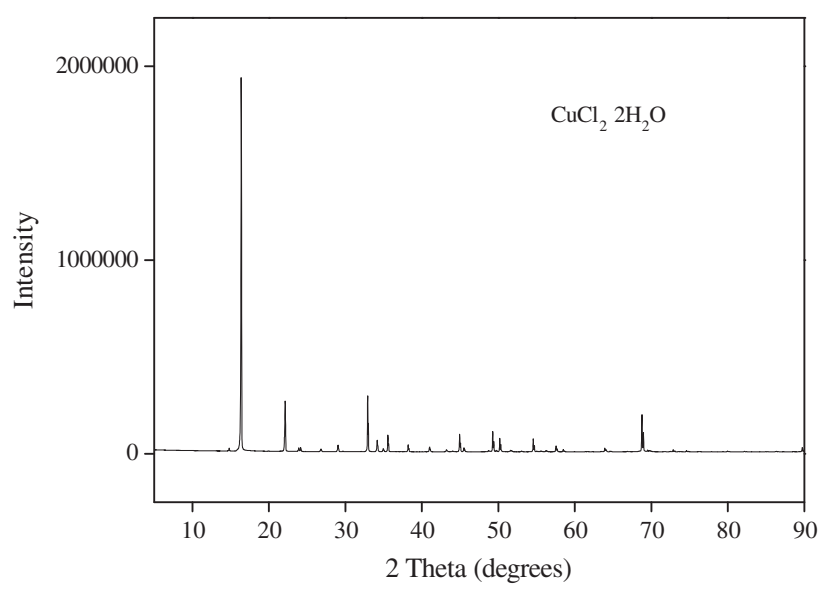

Fig. 6. X-ray diffraction patterns of the product obtained after the leaching solution was crystallized.

increasing reaction temperature, the leaching of $\mathrm{Cu}, \mathrm{Pb}, \mathrm{Sn}$ and $\mathrm{Cr}$ increased significantly. The leaching of $\mathrm{Cu}, \mathrm{Pb}, \mathrm{Sn}$ and $\mathrm{Cr}$ at $250{ }^{\circ} \mathrm{C}$ increased to $38 \%, 60 \%, 25 \%$, and $35 \%$, respectively.

At $250{ }^{\circ} \mathrm{C}$, the dechlorination of PVC reached 93\% (Fig. 1a). However, only $38 \%$ of the $\mathrm{Cu}$ was leached at $250{ }^{\circ} \mathrm{C}$. The possible reason is that a considerable portion of $\mathrm{Cu}$ cannot be oxidized at low temperature and may still exist as metallic $\mathrm{Cu}$ or be converted to its alloy phases with Sn according to the XRD analysis (Fig. 4a). Cu was completely oxidized with further increasing reaction temperature, leading to the significant increase of $\mathrm{Cu}$ leaching (>98\%) when the temperature was higher than $350^{\circ} \mathrm{C}$. Similarly, the leaching of $\mathrm{Pb}$ increased with further increasing temperature after $250^{\circ} \mathrm{C} . \mathrm{Pb}$ can form stable complexes with $\mathrm{Cl}^{-}$in the presence of excess $\mathrm{HCl}$. Therefore, with the remarkable increase of PVC dechlorination after $250{ }^{\circ} \mathrm{C}$ and the further enrichment of $\mathrm{HCl}$ in the reaction system, the $\mathrm{Pb}$ leaching increased. Approximately $80 \%$ of the $\mathrm{Pb}$ was leached at $350{ }^{\circ} \mathrm{C}$.

In contrast to $\mathrm{Cu}$ and $\mathrm{Pb}$, the leaching efficiencies of $\mathrm{Sn}$ and $\mathrm{Cr}$ decreased with increasing the reaction temperature after $250^{\circ} \mathrm{C}$. Particularly, the leaching of $\mathrm{Cr}$ decreased markedly and declined to a very low level $(<4 \%)$ after $350^{\circ} \mathrm{C}$. This may be attributed to that $\mathrm{Cr}$ was completely oxidized to chromate with increasing the reaction temperature, and the formed chromate reacted with $\mathrm{Pb}$ (approximately $80 \%$ of the $\mathrm{Pb}$ was in the aqueous phase at $350{ }^{\circ} \mathrm{C}$, Fig. 7) to produce insoluble $\mathrm{PbCrO}_{4}$, resulting in the very low leaching of $\mathrm{Cr}$. The low leaching efficiency of $\mathrm{Sn}$ at $250^{\circ} \mathrm{C}$

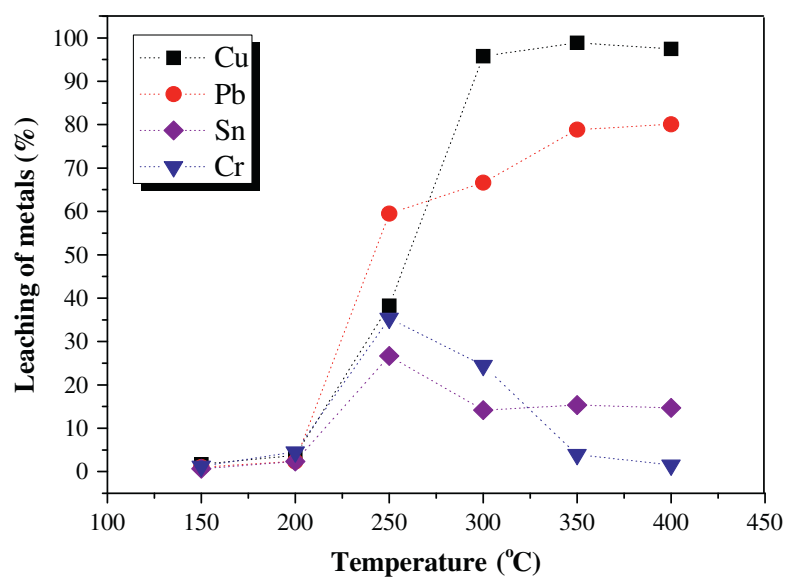

Fig. 7. Effect of co-treatment temperature on the leaching of different metals $(\mathrm{PVC}: \mathrm{PCBs}=1: 1$, reaction time $=60 \mathrm{~min}$, solid-liquid ratio $=1: 9)$.
(25\%) can be attributed to the oxidation of $\mathrm{Sn}$ from $\mathrm{Sn}^{0}$ to $\mathrm{SnO}_{2}$ (Fig. 4a), which is more difficult to be leached in $\mathrm{HCl}$ compared to $\mathrm{Sn}^{0}$. When the reaction temperature was $>250^{\circ} \mathrm{C}$, the Sn leaching further decreased with increasing reaction temperature, which could be due to the complete transformation of $\mathrm{Sn}$ from $\mathrm{Sn}^{0}$ to $\mathrm{SnO}_{2}$ (Fig. 4b).

\subsection{Effect of residence time on the leaching of different metals in SBWO co-treatment}

The effect of co-treatment time on the leaching of different metals at $350{ }^{\circ} \mathrm{C}$ is shown in Fig. 8. During the first $30 \mathrm{~min}$ of reaction, $84.7 \%$ of the $\mathrm{Cu}, 77.4 \%$ of the $\mathrm{Pb}, 25.5 \%$ of the $\mathrm{Sn}$, and $33.6 \%$ of the $\mathrm{Cr}$ were converted from insoluble to soluble species in co-treatment process. When the residence time was increased to $60 \mathrm{~min}$, the leaching of $\mathrm{Sn}$ and $\mathrm{Cr}$ tended to decrease significantly. The leaching efficiencies of $\mathrm{Sn}$ and $\mathrm{Cr}$ declined to $15.3 \%$ and 3.9\%, respectively. With further increasing residence time ( $>60 \mathrm{~min}$ ), there was little change in the $\mathrm{Sn}$ and $\mathrm{Cr}$ leaching. Little $\mathrm{Cr}$ could be detected in the aqueous phase after 60 -min reaction, indicating the complete immobilization of $\mathrm{Cr}$ in solid residue. It can be found in Fig. 8 that during the first $60 \mathrm{~min}$ of co-treatment, $\mathrm{Sn}$ and $\mathrm{Cr}$ experienced a stage from partial leaching to re-immobilization. During the first 30 min of co-treatment process, part of the Sn and $\mathrm{Cr}$ might still remain in the metallic form, resulting in their part leaching at this reaction stage. With further increasing residence time, $\mathrm{Sn}$ and $\mathrm{Cr}$ were converted into their insoluble species, leading to the decrease of leaching efficiencies. The high mole ratio of $\mathrm{Pb} / \mathrm{Cr}$ led to a very low concentration of soluble $\mathrm{Cr}$ for the 60-min residence time. The complete oxidation of $\mathrm{Sn}$ from $\mathrm{Sn}^{0}$ to $\mathrm{SnO}_{2}$ resulted in the decrease of $\mathrm{Sn}$ leaching after $60 \mathrm{~min}$ residence time.

There was little change in the Pb leaching during all of the residence times studied. Fig. 1b indicated that $30 \mathrm{~min}$ was sufficient for all of the $\mathrm{Cl}$ in PVC to be dissolved as $\mathrm{HCl}$ in water in SBWO process. The excess $\mathrm{HCl}$ in system could form stable complexes with $\mathrm{Pb}$ and led to a higher leaching of $\mathrm{Pb}$ at the first $30 \mathrm{~min}$ of reaction.

Interestingly, during the whole reaction process, $\mathrm{Cu}$ experienced the process of leaching enhancement-leaching reducing (re-immobilization). The $60 \mathrm{~min}$ residence time was the turning point. However, the re-immobilization tendency of $\mathrm{Cu}$ was slight. Only a very small part of the $\mathrm{Cu}$ was re-immobilized. It has been reported that $\mathrm{Cu}^{2+}$ species can be used as an oxidation catalyst in SBWO process of organics [31]. It was observed that the $\mathrm{Cu}^{2+}$ was reduced to $\mathrm{Cu}^{+}$during the catalytic reaction in the SBWO process, and the $\mathrm{Cu}^{+}$was re-oxidized by the oxidant $\left(\mathrm{O}_{2}\right)$ in the subcritical water [31]. In our experiment $\left(350^{\circ} \mathrm{C}, \mathrm{PVC}: \mathrm{PCBs}=1: 1\right)$,

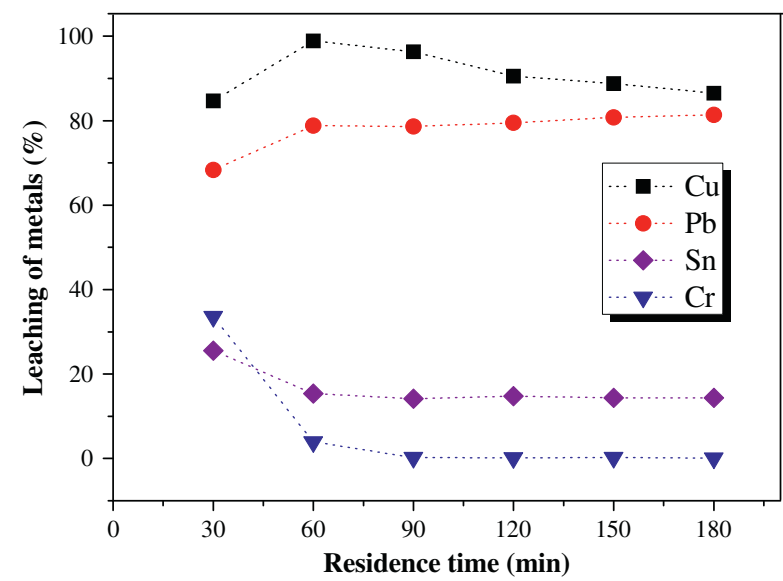

Fig. 8. Effect of co-treatment time on the leaching of different metals (PVC: $\mathrm{PCBs}=1: 1$, reaction temperature $=350^{\circ} \mathrm{C}$, solid-liquid ratio $=1: 9$ ). 
$\mathrm{Cu}$ was completely oxidized and leached in $\mathrm{HCl}$ to form copper chloride. Part of the $\mathrm{Cu}^{2+}$ species (copper chloride) could act as a catalyst and be reduced to $\mathrm{Cu}^{+}$species along with the oxidation of organics in the system. The re-oxidation of $\mathrm{Cu}^{+}$species to $\mathrm{Cu}^{2+}$ species such as $\mathrm{CuO}$ in the presence of the oxygen in system could result in the re-immobilization of partial $\mathrm{Cu}$. On the other hand, the formed $\mathrm{Cu}^{2+}$ species could be precipitated from system due to its low solubility in subcritical water and might enter the mineral crystal lattice of the residual solid particles of waste PCBs, which also lowered the $\mathrm{Cu}$ leaching activity.

\subsection{Effect of solid-liquid ratio on the leaching of different metals in SBWO co-treatment}

To investigate the effect of pulp ratio on the leaching of metals, different water volumes were used in the experiments, and the results are shown in Fig. 9. In every experiment, PCBs and PVC were fixed at $5 \mathrm{~g}$, respectively, and hydrogen peroxide was fixed at $40 \mathrm{ml}$. The volume of water was controlled at 10, 20, 30, 40, 50, and $60 \mathrm{ml}$, respectively. Therefore, the solid-liquid ratio was $1: 5$, $1: 6,1: 7,1: 8,1: 9$, and 1:10 g/ml, respectively. From Fig. 9, it can be found that solid-liquid ratio plays an important role in the leaching efficiency of metals, especially for $\mathrm{Cu}$ and $\mathrm{Pb}$. From Fig. 9, it can be found that the leaching efficiencies of $\mathrm{Cu}$ and $\mathrm{Pb}$ increased with the increase of the volume of water.

The volume of water in the reactor is directly related to the reaction pressure. The system pressure increased with increasing the water volume. With the increase of system pressure, the nature of the subcritical water changed significantly: the density and viscosity of the subcritical water decreased rapidly while the diffusivity and mass transport coefficient increased. As a result, BFRs and PVC could be quickly decomposed into low molecular weight organic compounds and oxidized in the subcritical water, and the dehalogenation efficiency increased. With the removal of organic matters contained in PCBs, the metals embedded were exposed to the lixiviant in the reaction system, which markedly enlarged the contact area and enhanced the leaching of metals. On the other hand, a higher pressure environment also may be favorable for improving the mass transfer efficiency of the leaching reaction of metals during the SBWO co-treatment process. Hence, a higher leaching efficiency of metals could be obtained in a higher volume of water. However, if further increasing the water volume, the $\mathrm{HCl}$ decomposed from PVC could be diluted and the increase of metals leaching was negligible (Fig. 9, solid-liquid ratio $=1: 10 \mathrm{~g} / \mathrm{ml}$ ). Therefore, the solid-liquid ratio was controlled at $1: 9 \mathrm{~g} / \mathrm{ml}$ in this study.



Fig. 9. Effect of solid-liquid ratio on the leaching of different metals (PVC: $\mathrm{PCBs}=1: 1$, reaction temperature $=350^{\circ} \mathrm{C}$, reaction time $=60 \mathrm{~min}$ ).

\subsection{Effect of SBWO co-treatment on the crystalline phases of the solid} residues

Fig. 4a and b show X-ray diffraction spectra measured for the solid residues of waste PCBs and PVC co-treated at $200{ }^{\circ} \mathrm{C}$ and $400{ }^{\circ} \mathrm{C}$, respectively. In the XRD pattern for $200{ }^{\circ} \mathrm{C}$ (Fig. $4 \mathrm{a}$ ), highintensity diffraction peaks from $\mathrm{Cu}, \mathrm{CuSn}$, and $\mathrm{SnO}_{2}$ are indentified. Although noticeable $\mathrm{SnO}_{2}$ is still observed in the spectra for the residue treated at $400{ }^{\circ} \mathrm{C}$, the diffraction peaks from $\mathrm{Cu}$ and $\mathrm{CuSn}$ completely disappear for the residue (Fig. $4 \mathrm{~b}$ ).

It has been reported that $\mathrm{CuO}$ and $\mathrm{Cu}_{2} \mathrm{O}$ were formed during supercritical water oxidation treatment of waste PCBs [19,32], but crystalline phases of these copper compounds were not found in this study when the waste PCBs and PVC were co-treated at $200{ }^{\circ} \mathrm{C}$ and $400{ }^{\circ} \mathrm{C}$. The diffraction spectra in Fig. 4a and b clearly indicated the conversion of $\mathrm{Cu}$ from insoluble species into soluble species during the SBWO co-treatment process. It seemed that the oxygen produced from $\mathrm{H}_{2} \mathrm{O}_{2}$ was inclined to be used for the oxidation of $\mathrm{Sn}$ and organic matters contained in waste PCBs, and Cu element was converted to alloy substances with other metals such as $\mathrm{Sn}$ at lower temperature $\left(200^{\circ} \mathrm{C}\right)$. We inferred that copper was oxidized with the increase of reaction temperature, and then was leached rapidly in the presence of $\mathrm{HCl}$ decomposed from PVC. Hence, we cannot find the crystalline phases of copper oxides from the XRD spectra. We can conclude that the oxidation and leaching of $\mathrm{Cu}$ can be achieved simultaneously at higher temperature region of SBWO co-treatment.

Inversely, a considerable part of Sn element could be efficiently oxidized to $\mathrm{SnO}_{2}$ at low temperature, even at $200{ }^{\circ} \mathrm{C}$. High-intensity diffraction peaks from $\mathrm{SnO}_{2}$ could still be found at $400{ }^{\circ} \mathrm{C}$, indicating that $\mathrm{Sn}$ was completely immobilized in the residue after co-treatment. It is well known that metallic Sn can be leached in $\mathrm{HCl}$, but it is difficult for $\mathrm{SnO}_{2}$ to be leached in $\mathrm{HCl}$ due to that $\mathrm{SnCl}_{4}$ can only exist in the strong acid system whose $\mathrm{pH}$ is $<1.2$. However, the $\mathrm{pH}$ was approximately 1.8 under the reaction conditions used. In addition, it is difficult for the redox reactions between $\mathrm{SnO}_{2}$ and $\mathrm{HCl}$ to take place as the $\Delta G^{o}$ values of the reactions between $\mathrm{SnO}_{2}$ and $\mathrm{HCl}$ for $200^{\circ} \mathrm{C}$ and $400{ }^{\circ} \mathrm{C}$ are 381 and $611 \mathrm{~kJ} / \mathrm{mol}$, respectively.

$\mathrm{SnO}_{2}+4 \mathrm{HCl}=\mathrm{SnCl}_{2}+2 \mathrm{H}_{2} \mathrm{O}+\mathrm{Cl}_{2} \quad \Delta G_{200}^{o}=381 \mathrm{~kJ} / \mathrm{mol}$
$\mathrm{SnO}_{2}+4 \mathrm{HCl}=\mathrm{SnCl}_{2}+2 \mathrm{H}_{2} \mathrm{O}+\mathrm{Cl}_{2} \quad \Delta G_{400}^{o}=611 \mathrm{~kJ} / \mathrm{mol}$

\subsection{Environmental effects of SBWO co-treatment process}

Waste PCBs contain high amount of BFRs and heavy metals which may bring a series of environmental and health problems. In addition, improper treatment of PVC can lead to the formation of chlorinated toxic organics such as dioxins. The debromination and dechlorination could be conducted safely in the proposed SBWO co-treatment process, with no discharge of toxic products. Simultaneously, most of the $\mathrm{Pb}$, which is the most important heavy metal in waste PCBs, could be leached and recovered due to the action of the hydrochloric acid released from the PVC wastes. On the other hand, water is the only reaction medium in the proposed co-treatment process, and the toxic organic matters in waste PCBs can be decomposed effectively into $\mathrm{CO}_{2}$ and water, which markedly reduce the environmental risk of process. Hence, the SBWO co-treatment is an environment-friendly process for the treatment of both PCBs and PVC wastes.

\section{Conclusions}

An effective and green SBWO process was developed for simultaneously treating waste PCBs and PVC in this study. Water was 
the only reaction medium, and no hazardous reagent was needed in the process. The PVC waste could be treated safely in the proposed process. The PVC dechlorination was complete when temperature was $>300{ }^{\circ} \mathrm{C}$ and all of the $\mathrm{Cl}$ decomposed from PVC was dissolved as $\mathrm{HCl}$ in water, which was efficient for the leaching of $\mathrm{Cu}$ and $\mathrm{Pb}$ contained in waste PCBs owing to their conversion from insoluble metal species to water-soluble chlorides. Inversely, the Sn was immobilized in the residue after co-treatment due to that $\mathrm{Sn}$ was oxidized to $\mathrm{SnO}_{2}$ quickly even at low temperature in the co-treatment process. In the co-treatment, the BFRs contained in waste PCBs could be decomposed efficiently and all of the released $\mathrm{Br}$ could be enriched in water as $\mathrm{HBr}$, which eliminated the formation of toxic brominated organic compounds. The temperature region in which the $\mathrm{HBr}$ was released from BFRs was between 250 and $350^{\circ} \mathrm{C}$, which was lower than that of traditional thermal degradation process. The proposed process is high-efficiency not only for the recovery of $\mathrm{Cu}$ and $\mathrm{Pb}$ from waste PCBs, but also for the removal of BFRs contained in waste PCBs. No toxic organic products are discharged during the whole treatment, markedly reducing the environmental risk of the proposed process. The SBWO co-treatment offers a promising method for the simultaneous treatment of waste PCBs and PVC. The high concentration of $\mathrm{HCl}$ would lead to serious acidification and corrosion of the reactor. Hence, a demanding reactor material is needed in the proposed method, which may be the economic obstacle in a real process. The further studies of this work are in progress. For example: (1) the SBWO co-treatment of PVC waste and other metal-rich wastes such as electric arc furnace dust or spent batteries, and (2) the SBWO treatment of a real and complicated WEEE system, which simultaneously contains PVC plastics, brominated resins and multiple kinds of metals.

\section{Acknowledgements}

This research was financially supported by the Special Science Funding of Provincial Universities of Fujian (JK2012032), the Natural Science Foundation of Fujian Province (2011J05016), the Foundation of Fujian Educational Committee (JA11177 and JA12237), the Scientific Research Foundation of Fujian University of Technology (GY-Z10054 and GY-Z10071), and the Opening Project of Key Laboratory of Solid Waste Treatment and Resource Recycle (SWUST), Ministry of Education of China (11zxgk06).

\section{References}

[1] W. He, G. Li, X. Ma, H. Wang, J. Huang, M. Xu, WEEE recovery strategies and the WEEE treatment status in China, J. Hazard. Mater. B136 (3) (2006) 502-512.

[2] K. Huang, J. Guo, Z. Xu, Recycling of waste printed circuit boards: a review of current technologies and treatment status in China, J. Hazard. Mater. 164 (2009) 399-408.

[3] J. Guan, Y.-S. Li, M.-X. Lu, Product characterization of waste printed circuit board by pyrolysis, J. Anal. Appl. Pyrolysis 83 (2008) 185-189.

[4] H. Duan, J. Li, Y. Liu, N. Yamazaki, W. Jiang, Characterization and inventory of PCDD/Fs and PBDD/Fs emissions from the incineration of waste printed circuit board, Environ. Sci. Technol. 45 (2011) 6322-6328.

[5] J. Li, H. Lu, J. Guo, Z. Xu, Y. Zhou, Recycle technology for recovering resources and products from waste printed circuit boards, Environ. Sci. Technol. 41 (2007) 1995-2000.

[6] X. Zhou, J. Guo, K. Lin, K. Huang, J. Deng, Leaching characteristics of heavy metals and brominated flame retardants from waste printed circuit boards, J. Hazard. Mater. 246-247 (2013) 96-102.
[7] J.-C. Lee, H.T. Song, J.-M. Yoo, Present status of the recycling of waste electrical and electronic equipment in Korea, Resour. Conserv. Recy. 50 (2007) 380-397.

[8] J. Moltó, S. Egea, J.A. Conesa, R. Font, Thermal decomposition of electronic wastes: mobile phone case and other parts, Waste Manage. 31 (2011) 25462552.

[9] T. Oishi, K. Koyama, S. Alam, Recovery of high purity copper cathode from printed circuit boards using ammoniacal sulfate or chloride solutions, Hydrometallurgy 89 (2007) 82-88.

[10] T. Havlik, D. Orac, M. Petranikova, A. Miskufova, F. Kukurugya, Z. Takacova, Leaching of copper and tin from used printed circuit boards after thermal treatment, J. Hazard. Mater. 183 (2010) 866-873.

[11] A. Tuncuk, V. Stazi, A. Akcil, E.Y. Yazici, H. Deveci, Aqueous metal recovery techniques from E-scrap: hydrometallurgy in recycling, Miner. Eng. 25 (2012) 28-37.

[12] N. Zhu, Y. Xiang, T. Zhang, P. Wu, Z. Dang, P. Li, J. Wu, Bioleaching of metal concentrates of waste printed circuit boards by mixed culture of acidophilic bacteria, J. Hazard. Mater. 192 (2011) 614-619.

[13] D. Pant, D. Joshi, M.K. Upreti, R.K. Kotnala, Chemical and biological extraction of metals present in E waste: a hybrid technology, Waste Manage. 32 (2012) 979-990.

[14] L. Zhan, Z. Xu, Application of vacuum metallurgy to separate pure metal from mixed metallic particles of crushed waste printed circuit board scraps, Environ. Sci. Technol. 42 (2008) 7676-7681.

[15] I.O. Ogunniyi, M.K.G. Vermaak, Improving printed circuit board physical processing - an overview, in: Proceedings of European Metallurgical Conference, Dusseldorf, Germany, 2007, pp. 1645-1656.

[16] I.O. Ogunniyi, M.K.G. Vermaak, Investigation of froth flotation for beneficiation of printed circuit board comminution fines, Miner. Eng. 22 (2009) 378-385.

[17] N.-M. Zhu, C.-F. Wang, F.-S. Zhang, An integrated two-stage process for effective dechlorination of polychlorinated biphenyls in subcritical water in the presence of hydrogen donors, Chem. Eng. J. 197 (2012) 135-142.

[18] R. Pinero-Hernanz, C. Dodds, J. Hyde, J. García-Serna, M. Poliakoff, E. Lester, M.J. Cocero, S. Kingman, S. Pickering, K.H. Wong, Chemical recycling of carbon fibre reinforced composites in near critical and supercritical water, Composites: Part A 39 (2008) 454-461.

[19] L. Qadariyah, M. Sumarno, S. Machmudah, Wahyudiono, M. Sasaki, M. Goto, Degradation of glycerol using hydrothermal process, Bioresour. Technol. 102 (2011) 9267-9271.

[20] J.A. Onwudili, P.T. Williams, Alkaline reforming of brominated fire-retardant plastics: fate of bromine and antimony, Chemosphere 74 (2009) 787-796.

[21] J.A. Onwudili, P.T. Williams, Degradation of brominated flame-retarded plastics (Br-ABS and Br-HIPS) in supercritical water, J. Supercrit. Fluid. 49 (2009) 356-368.

[22] J. Yin, G. Li, W. He, J. Huang, M. Xu, Hydrothermal decomposition of brominated epoxy resin in waste printed circuit boards, J. Anal. Appl. Pyrolysis 92 (2011) 131-136.

[23] M. Xing, F.-S. Zhang, Degradation of brominated epoxy resin and metal recovery from waste printed circuit boards through batch sub/supercritical water treatments, Chem. Eng. J. 219 (2013) 131-136.

[24] F.-R. Xiu, Y. Qi, F.-S. Zhang, Recovery of metals from waste printed circuit boards by supercritical water pre-treatment combined with acid leaching process, Waste Manage. 33 (2013) 1251-1257.

[25] Y. Takeshita, K. Kato, K. Takahashi, Y. Sato, S. Nishi, Basic study on treatment of waste polyvinyl chloride plastics by hydrothermal decomposition in subcritical and supercritical regions, J. Supercrit. Fluid. 31 (2004) 185-193.

[26] K. Endo, Decomposition of polyvinyl chloride by water in high temperature and pressure, Polym. Appl. 50 (2001) 434-438.

[27] J. Li, H. Duan, K. Yu, L. Liu, S. Wang, Characteristic of low-temperature pyrolysis of printed circuit boards subjected to various atmosphere, Resour. Conserv. Recy. 54 (2010) 810-815.

[28] A. Kruse, E. Dinjus, Hot compressed water as reaction medium and reactant: properties and synthesis reactions, J. Supercrit. Fluid. 39 (2007) 362-380.

[29] D. Zimet, Behavior of chromium and lead in supercritical water oxidation environment, Master Thesis, Civil Engineering Department, The University of Texas at Austin, Austin, TX, 1995.

[30] F.-R. Xiu, F.-S. Zhang, Recovery of copper and lead from waste printed circuit boards by supercritical water oxidation combined with electrokinetic process, J. Hazard. Mater. 165 (2009) 1002-1007.

[31] A. Santos, P. Yustos, A. Quintanilla, G. Ruiz, F. Garcia-Ochoa, Study of the copper leaching in the wet oxidation of phenol with CuO-based catalysts: causes and effects, Appl. Catal. B: Environ. 61 (2005) 323-333.

[32] F.-R. Xiu, F.-S. Zhang, Size-controlled preparation of $\mathrm{Cu}_{2} \mathrm{O}$ nanoparticles from waste printed circuit boards by supercritical water combined with electrokinetic process, J. Hazard. Mater. 233-234 (2012) 200-206. 